\title{
Metabolic Effects of Mulberry Leaves: Exploring Potential Benefits in Type 2 Diabetes and Hyperuricemia
}

\author{
A. Hunyadi, ${ }^{1}$ E. Liktor-Busa, ${ }^{1}$ Á. Márki, ${ }^{2}$ A. Martins, ${ }^{3,4}$ N. Jedlinszki, ${ }^{1}$ \\ T. J. Hsieh, ${ }^{5}$ M. Báthori, ${ }^{1}$ J. Hohmann, ${ }^{1}$ and I. Zupkó ${ }^{2}$ \\ ${ }^{1}$ Institute of Pharmacognosy, Faculty of Pharmacy, University of Szeged, Eötvös u. 6, Szeged 6720, Hungary \\ ${ }^{2}$ Department of Pharmacodynamics and Biopharmacy, Faculty of Pharmacy, University of Szeged, Eötvös u. 6, Szeged 6720, Hungary \\ ${ }^{3}$ Department of Medical Microbiology and Immunobiology, Faculty of Medicine, University of Szeged, Dóm tér 13, \\ Szeged 6720, Hungary \\ ${ }^{4}$ Unidade de Parasitologia e Microbiologia Médica, Instituto de Higiene e Medicina Tropical, \\ Universidade Nova de Lisboa, Rua da Junqueira 100, 1349-008 Lisboa, Portugal \\ ${ }^{5}$ Department of Genome Medicine, College of Medicine, Kaohsiung Medical University, Shih Chuan 1st Rd. 100, Kaohsiung 807, Taiwan
}

Correspondence should be addressed to A. Hunyadi; hunyadi.a@pharm.u-szeged.hu and I. Zupkó; zupko@pharm.u-szeged.hu

Received 24 July 2013; Accepted 18 October 2013

Academic Editor: C. S. Cho

Copyright (C) 2013 A. Hunyadi et al. This is an open access article distributed under the Creative Commons Attribution License, which permits unrestricted use, distribution, and reproduction in any medium, provided the original work is properly cited.

\begin{abstract}
The leaves of Morus alba L. have a long history in Traditional Chinese Medicine and also became valued by the ethnopharmacology of many other cultures. The worldwide known antidiabetic use of the drug has been suggested to arise from a complex combination effect of various constituents. Moreover, the drug is also a potential antihyperuricemic agent. Considering that type 2 diabetes and hyperuricemia are vice-versa in each other's important risk factors, the use of mulberry originated phytotherapeutics might provide an excellent option for the prevention and/or treatment of both conditions. Here we report a series of relevant in vitro and in vivo studies on the bioactivity of an extract of mulberry leaves and its fractions obtained by a stepwise gradient on silica gel. In vivo antihyperglycemic and antihyperuricemic activity, plasma antioxidant status, as well as in vitro glucose consumption by adipocytes in the presence or absence of insulin, xanthine oxidase inhibition, free radical scavenging activity, and inhibition of lipid peroxidation were tested. Known bioactive constituents of $M$. alba (chlorogenic acid, rutin, isoquercitrin, and loliolide) were identified and quantified from the HPLC-DAD fingerprint chromatograms. Iminosugar contents were investigated by MS/MS, 1-deoxynojirimycin was quantified, and amounts of 2-O-alpha-D-galactopyranosyl-1-deoxynojirimicin and fagomine were additionally estimated.
\end{abstract}

\section{Introduction}

Chronically elevated uric acid concentration in the serum has impact on human health at various levels; it frequently leads to the development of gout [1], and it is a relevant risk factor of several further chronic diseases. For example, it represents a significant risk for various cardiovascular and cerebrovascular diseases [2-4], and a tight connection between hyperuricemia and diabetes has recently been revealed; apparently, these two diseases mutually increase each other's incidence [5]. Hyperinsulinemia in type 2 diabetes can significantly increase reabsorption of uric acid in the proximal tubules, while its overproduction due to an increased activity of xanthine-oxidase usually also takes place $[5,6]$. On the other hand, high uric acid levels might predict the development of metabolic syndrome consequentially leading to diabetes $[7,8]$ and can also increase severity of the already developed disease by leading to a higher incidence of certain diabetic complications [9]. The mechanism by which these metabolic states are interconnected seems yet to be clarified, although there is evidence that hyperuricemia, metabolic syndrome, and type II diabetes share the same causal origin in which insulin resistance would play a key role [5]. Anyhow, development of novel therapeutic agents targeting both diabetes 
and hyperuricemia appears to be a highly relevant strategy for overcoming difficulties attributed to the current therapeutic approaches. Appropriately chosen phytotherapeutics [10, 11], representing complex bioactivity profiles, might serve as excellent tools to fulfill this objective, either as monotherapy or in combination with already existing approaches.

Mulberry leaves are probably best known by their role in the silk production, but medicinal use of this drug also dates back at least two thousand years; it is already mentioned in the "Divine Farmer's Materia Medica" (pinyin: Shénnóng Běncǎo Jing) written during the reign of the Han dynasty. In Traditional Chinese Medicine, leaves of $M$. alba possess sweet, slightly bitter, and slightly cold properties, and their primary uses are described as "to expel wind and heat from the lungs, as well as to clear the liver and the eyes" [12]. Anti-diabetic use of mulberry leaves had also been popular; moreover, this indication became part of the local traditional medicine wherever the tree has been naturalized [13-16]. Based on this, a large number of herbal preparations (including many food supplements) are worldwide available for diabetes treatment and easily accessible to everyone even via online shopping. This activity of mulberry leaves has been verified by a number of studies including several animal experiments [14-16] and a few human trials as well $[17,18]$, but, to our knowledge, the active constituents and their role in the activity still remain to be fully described. Nevertheless, a complex cocktail of various bioactive constituents is thought to be responsible for this activity [19], among which the role of iminosugars [18] and certain phenolics mainly chlorogenic acid and rutin [16] might be the most significant.

Furthermore, several traditional Chinese preparations utilize the branch of Morus alba for the treatment of gout, arthritis, and rheumatism [20]. Various constituents of the drug were found to have significant antihyperuricemic potential, including mulberroside A, a stilbene glycoside [21], and a number of flavonoids, primarily morin $[22,23]$.

Based on the above, our objectives were to explore the potential of Morus alba leaves as dual-target phytotherapeutics to prevent and treat both diabetes and hyperuricemia and to investigate whether a simple chromatographic fractionation can lead to the enrichment of the main bioactive constituents valuable for both therapeutic targets of interest.

\section{Materials and Methods}

2.1. Plant Material, Chemicals, and Reagents. The leaves of Morus alba were collected near Ásotthalom (nearby Szeged, Hungary) in May, 2007, and botanically identified by A. Hunyadi. A voucher specimen (MA052007) was deposited in the Institute of Pharmacognosy, University of Szeged, Szeged, Hungary. All chemicals, if otherwise not specified, were purchased from Sigma-Aldrich (Budapest, Hungary). Rutin (2) and isoquercitrin (3) were purchased from ChromaDex (Irvine, CA, USA) and Extrasynthése (Genay, France), respectively. Loliolide (4) was previously isolated from the dry leaves of Morus alba [19], and 1-Deoxynojirimicin (1-DN) was purchased from Wako Pure Chemical Industries (Osaka, Japan). HPLC grade methanol was obtained from Fischer
Scientific; ultrapure water was obtained by using a Millipore Direct-Q UV3 equipment.

2.2. Extraction and Chromatographic Fractionation. $2.5 \mathrm{~kg}$ of the dried and ground plant material was extracted by percolation with $30 \mathrm{~L}$ of $70 \%$ aqueous methanol and the solvent was evaporated under vacuum at $50^{\circ} \mathrm{C}$ to obtain $675.36 \mathrm{~g}$ dry extract (EX). $170 \mathrm{~g}$ of the dry material was further processed; it was dissolved in $1000 \mathrm{~mL}$ of water and extracted with $10 \times 500 \mathrm{~mL}$ of $\mathrm{n}$-butanol. After solvent evaporation, dry residue of the aqueous (FR-W) and organic phase (FRB) was 78.4 and $88.09 \mathrm{~g}$, respectively. The butanol phase was adsorbed onto triple amount (276 g) of silica (Kieselgel 60, Merck, Darmstadt, Germany) and administered on the top of a previously prepared silica column of $1840 \mathrm{~g}$. A stepwise gradient of $\mathrm{CH}_{2} \mathrm{Cl}_{2}, \mathrm{CH}_{2} \mathrm{Cl}_{2}: \mathrm{EtOH}(95: 5,9: 1,8: 2,7: 3$, $6: 4$, and $1: 1$ ), and $\mathrm{EtOH}$ was used, and one single fraction per solvent was collected. After the first fraction of $18 \mathrm{~L}$, each following was of $10 \mathrm{~L}$ volume. After solvent evaporation, dry residues of the fractions were 13.72, 9.76, 4.48, 8.19, 10.52, 9.93, 5.50 , and $10.87 \mathrm{~g}$, respectively. Based on high similarities in their TLC fingerprints, the last three fractions were joined; hence, finally six fractions, referred to as FR1-6, were used for the experiments discussed here.

2.3. HPLC-DAD Analysis of Fractions FR1-6. Diode-array detected high performance liquid chromatography (HPLCDAD) was performed on a gradient system of two Jasco PU2080 pumps connected to a Jasco MD-2010 Plus diodearray detector (DAD) and equipped with a Jasco AS2055Plus autosampler (Jasco Co., Tokyo, Japan), by using a Zorbax Eclipse XDB-C8 $(5 \mu \mathrm{m}, 4.6 \times 150 \mathrm{~mm})$ analytical column. Samples were dissolved in $30 \%$ of aqueous $\mathrm{MeOH}$ at $2 \mathrm{mg} / \mathrm{mL}$, and $30 \mu \mathrm{L}$ of each was injected. Gradient elution was performed from 30 to $100 \%$ of aqueous $\mathrm{MeOH}$ in 13 minutes, kept at $100 \%$ for four more minutes, and returned to $30 \%$ at $17.1 \mathrm{~min}$. Chromatograms were recorded for $24 \mathrm{~min}$, and DAD data was collected from 200 to $650 \mathrm{~nm}$. Baselines were corrected by subtracting the chromatogram of a single $30 \mu \mathrm{L}$ injection of $30 \% \mathrm{MeOH}$.

2.4. Quantitative Analysis of Compounds 1-4. Single-point quantitative analysis was performed for the previously identified major constituents in their respective fractions such as chlorogenic acid (1), rutin (2), and isoquercitrin (3) in EX, FR-B and FR5-6 and loliolide (4) in FR2. Calibration curves were taken by analysing dilutions of a $1 \mathrm{mg} / \mathrm{mL}$ stock solution of the corresponding standard, at concentrations of 1 , $0.5,0.4,0.3,0.2,0.1$, and $0.05 \mathrm{mg} / \mathrm{mL} . R^{2}$ values were 0.9970 , $0.9990,0.9904$, and 0.9978 for the calibration lines of $\mathbf{1 - 4}$, respectively. In case of FR5 and FR6, peaks of $\mathbf{2}$ and $\mathbf{3}$ were partially overlapping; deconvolution was performed by using Gaussian approximations with the Fityk 0.9.7 software (Free Software Foundation, Poland) and quantities were calculated based on the peak areas revealed this way.

2.5. Determination of Iminosugars. Iminosugar content was qualitatively investigated by thin-layer chromatography 
(TLC) in each fraction, by using DC-Alufolien Kieselgel $60 \mathrm{~F}_{254}$ plates (Merck, Darmstadt, Germany) and $\mathrm{CH}_{2} \mathrm{Cl}_{2}$ : $\mathrm{MeOH}: \mathrm{NH}_{3}(3: 6: 2, \mathrm{v} / \mathrm{v} / \mathrm{v})$ as solvent system. For quantitative analysis, an API $2000 \mathrm{MS} / \mathrm{MS}$ spectrometer was used with a Shimadzu autosampler and an electrospray ionization (ESI) interface set in positive mode. 1-DN, 2-O-alpha-Dgalactopyranosyl-1-deoxynojirimicin (Gal-DN), and fagomine contents were investigated in FR-W, FR-B, and FR4-6. Injected samples were washed into the spectrometer with $50 \%$ aqueous $\mathrm{MeOH}$ at a flow rate of $200 \mu \mathrm{L} / \mathrm{min}$; temperature of the ion source was $300^{\circ} \mathrm{C}$. Multiple reaction monitoring $(\mathrm{MRM})$ was used with transitions of $m / z 164 \rightarrow 69$ for 1-DN, $\mathrm{m} / \mathrm{z} 326 \rightarrow 164$ for GAL-DN, and $m / z 148 \rightarrow 86$ for fagomine, according to literature data [24]. Parameter optimization and data acquisition and evaluation were performed by using the Analyst 1.5.1 software. Calibration line of 1-DN $\left(R^{2}=1.0000\right)$ was obtained by means of six measurement points in triplicates.

2.6. In Vitro Assay on Xanthine Oxidase (EC 1.17.3.2) Inhibition. The activity of the enzyme was calculated from the increase of uric acid concentration determined by microplate-based kinetic photometry [25]. Briefly, the absorption of uric acid generated from xanthine $(50 \mu \mathrm{M}$ at start-up) was followed at $\lambda=290 \mathrm{~nm}$ for $125 \mathrm{~s}$ (Spectrostar Nano, BMG Labtech, Ortenberg, Germany). The activity of xanthine oxidase was described as the slope of the absorbance versus time curve and allopurinol was used as positive control. Stock solutions prepared with dimethylsulfoxide were used for the in vitro assays and any substantial effect of the solvent was excluded. All in vitro assays were carried out in duplicates.

2.7. Determination of Free Radical Scavenging Activity by DPPH Assay In Vitro. The activity for scavenging 1,1diphenyl-2-picrylhydrazyl (DPPH) radicals was tested for each fraction as described earlier [26]. Briefly, different amounts of the samples were added to $0.1 \mathrm{mM}$ DPPH dissolved in ethanol. The mixture was shaken and allowed to stand for $30 \mathrm{~min}$, and then the absorbance of the solution was measured at $\lambda=517 \mathrm{~nm}$. trolox (6-hydroxy-2,5,7,8tetramethylchroman-2-carboxylic acid), a water-soluble ana$\log$ of vitamin E, was used as positive control.

2.8. Determination of Lipid Peroxidation Inhibitory Activity. The antioxidant properties of the fractions were additionally measured by means of inhibition of the autooxidation of unsaturated fatty acids present in animal brain tissue [27]. A lipid-rich fraction was prepared from the brains of male Sprague-Dawley rats (Charles River Laboratories, Budapest, Hungary; body mass: 250-300 g) by homogenization and centrifugation. The fatty acids in such a fraction get spontaneously oxidized during an incubation of $1 \mathrm{~h}$ at $37^{\circ} \mathrm{C}$, and this oxidation can be inhibited by antioxidants. The oxidized products were determined by colorimetry at $532 \mathrm{~nm}$ after reaction with thiobarbituric acid. All in vitro experiments were carried out in duplicates and statistically evaluated. Sigmoid curves were fitted to the results of both antioxidant assays, and $\mathrm{IC}_{50}$ values were calculated by using GraphPad Prism 4 (GraphPad Software, San Diego, CA, USA).

2.9. Testing the Effect on the Glucose Consumption of Adipocytes. Effect of each fraction was tested on the in vitro glucose consumption of adipocytes as published before, at concentrations of $200 \mu \mathrm{g} / \mathrm{mL}$ [19]. Briefly, 3T3-L1 preadipocytes $\left(5 \times 10^{5}\right.$ cells, BCRC no. 60159; Bioresource Collection and Research Center, Taiwan) were seeded and cultured in 10\% CS DMEM containing $5.5 \mathrm{mM} \mathrm{D}$-glucose. The cells were induced to differentiate, and, at day 3 , samples dissolved in DMSO were added to the cells at $200 \mu \mathrm{g} / \mathrm{mL}$ either in presence or absence of $0.32 \mu \mathrm{M}$ insulin. $24 \mathrm{~h}$ changes in the glucose contents of the testing media were recorded and compared to those before the addition of the samples.

2.10. Animal Studies. Animals were treated in accordance with the European Communities Council Directives (86/609/ECC) and the Hungarian Act for the Protection of Animals in Research (XXVIII.tv.32.§). Experiments involving animal subjects were carried out with the approval of the Hungarian Ethical Committee for Animal Research (registration no. IV./01758-2/2008). Male Sprague-Dawley rats (Charles River Laboratories, Budapest, Hungary; body mass: $180-200 \mathrm{~g} ; 8$ animals in each group) were housed in temperature $\left(20-23^{\circ} \mathrm{C}\right)$, humidity $(40-60 \%)$, and light $(12 \mathrm{~h}$ of light, $12 \mathrm{~h}$ of dark) regulated rooms, with tap water and rodent food (Bioplan, Isaszeg, Hungary) intake available ad libitum. The tested extracts were orally administered in $0.25 \%$ methylcellulose containing $2 \%$ Cremophor EL using a dosing volume of $5 \mathrm{~mL} / \mathrm{kg}$. Three doses of all extracts (30, 60 , and $120 \mathrm{mg} / \mathrm{kg}$ ) were selected for daily treatment for 3 consecutive days and each treatment was performed after 16 hours of fasting. One-way analysis of variance (ANOVA) with Dunnett's multiple comparison test by GraphPad Prism 4 was used for statistical evaluation of all in vivo experiments.

2.11. Determination of Antihyperuricemic, Antihyperglycemic, and Antioxidant Properties of the Fractions In Vivo. In order to minimize the number of animals, antihyperuricemic, antihyperglycemic, and antioxidant properties effects were determined from the same groups of rats. Experimental hyperuricemia model induced by uricase inhibitor potassium oxonate was utilized to assess the antihyperuricemic properties of the tested fractions [28]. $250 \mathrm{mg} / \mathrm{kg}$ potassium oxonate was suspended in $0.25 \%$ methylcellulose and administered intraperitoneally at the time of the third oral treatment. $50 \mathrm{mg} / \mathrm{kg}$ of allopurinol, a clinically used antigout drug, was orally administered as a positive control. One hour later rats were orally treated with $2.5 \mathrm{~g} / \mathrm{kg}$ starch suspension in a dosing volume of $5 \mathrm{~mL} / \mathrm{kg}$ in order to characterize the antihyperglycemic effects of the fractions [25]. After another one hour, venous blood samples were obtained from the tail, and the plasma glucose concentrations were determined by a commercially available kit (Reanal, Budapest, Hungary) based on the glucose oxidase-peroxidase method [29]. Immediately after blood sampling, rats were anesthetized in $4 \%$ isoflurane and additional blood samples were collected by 
cardiac puncture for determination of uric acid concentration and total antioxidant capacity. Since inhalational anesthetics are reported to substantially elevate the blood glucose level, separate blood samplings were needed for determination of all the planned parameters [30]. Serum samples were prepared by centrifugation and stored at $-70^{\circ} \mathrm{C}$ until the analyses. All determinations by colorimetric uric acid (BioAassay Systems, Hayward, CA, USA) and antioxidant (Sigma-Aldrich, Budapest, Hungary) assay kits were performed in duplicates according to the manufacturers' suggestions. Separate groups orally treated with glibenclamide and trolox $(10 \mathrm{mg} / \mathrm{kg}$ for both) were included as reference for the antihyperglycemic and antioxidant assays, respectively.

\section{Results and Discussion}

3.1. Chemical Composition of the Fractions Obtained. The fractions, obtained by solvent-solvent extraction and a rough chromatographic separation of the organic phase on silica, represented fundamentally different chemical compositions (Figure 1). As expected, highly water soluble, hydrophilic compounds (including iminosugars of the plant, see below) remained in the water phase (Figure 1(b)), while most of the still polar chlorogenic acid (1) could already be detected in the organic phase (Figure 1(c)) along with vast majority of the supposedly "drug-like" secondary metabolites of mulberry leaves. These would be the compounds with the highest probability for therapeutic value; mainly the too low $\log P$ value typically results in poor penetration through membranes (iminosugars, a constituent group of possible exception to this, are discussed below). As seen from the DAD fingerprints, FR1 (Figure 1(d)) and FR2 (Figure 1(e)) mostly contained compounds with lower wavelengths of UV absorbance maxima probably including several terpenoids and/or phenylpropanes [19]. The dominant peak of FR2 was detected and quantified as loliolide (4) (0.33\%), a monoterpene lactone we have recently reported from $M$. alba leaves [19]. Of all fractions, FR3 (Figure 1(f)) contained the smallest amount of UV absorbing material; its main constituents remained unidentified. Based on its UV spectrum and retention time, chief constituent of FR4 (Figure $1(\mathrm{~g})$ ) is suggested to be a flavone aglycone (3.42-3.50\%, expressed in equivalents of isoquercitrin (3) or rutin (2)), while $3(2.42 \%)$ was also present in this fraction. FR5 (Figure 1(h)) contained the majority of $3(9.79 \%)$ along with a smaller amount of $2(3.77 \%)$, while the previously mentioned unidentified flavonoid could still be detected. FR6 (Figure 1(i)), the most polar fraction obtained from the column chromatography, contained 1 (8.99\%), 2 (10.41\%), and 3 (5.64\%) as major UV active constituents.

Both the extract and the fractions contained very small amounts of iminosugars. By means of MS/MS, 1-DN contents were found as low as $0.2694 \%$ o (EX), $0.3007 \%$ o (FR-W), $0.0742 \%$ (FR-B), $\sim 0.016 \%$ (FR4; around detection limit), $0.0558 \%$ (FR5), and $0.2770 \%$ (FR6). On the other hand, slope of the calibration lines of GAL-DN and fagomine is around 13 and 6 times higher, respectively, as compared to that of $1-\mathrm{DN}$, based on a recent publication using the same MRM transitions with ESI-MS/MS [24]. This allowed only a rough estimation on the quantity of these compounds by using our calibration obtained for 1-DN. Amounts of GALDN were about $0.02 \%$ (EX), $0.03 \%$ (FR-W), $0.003 \%$ (FRB) and $0.009 \%$ (FR6), and trace amounts of this compound were detected in FR4 and FR5. Fagomine contents could be estimated as around $0.03 \%$ (EX), 0.04\%o (FR-W), $0.01 \%$ o (FR-B), $0.01 \%$ (FR5) and $0.03 \%$ (FR6), with a trace amount of this compound also present in FR4. Structures of the compounds identified from the fractions are shown in Figure 2.

3.2. Inhibition of Xanthin Oxidase In Vitro. All fractions were tested at the final concentration of $5 \mu \mathrm{g} / \mathrm{mL}$. The enzyme activity determined in the solvent-treated condition was considered $100 \%$ and all other conditions were compared to that control. None of the prepared fractions exerted any substantial action on the enzyme xanthine oxidase, while, as expected, the reference compound allopurinol resulted in a nearly complete $(>90 \%)$ inhibition of the enzyme activity at $5 \mu \mathrm{g} / \mathrm{mL}$, and its $\mathrm{IC}_{50}$ value was determined as $1.03 \mu \mathrm{g} / \mathrm{mL}$. Based on these results, $\mathrm{XO}$ inhibition does not seem to be an important mechanism for neither the antihyperuricemic nor the antioxidant activity of mulberry preparations.

3.3. In Vitro Antioxidant Properties. Two different bioassays were utilized to investigate the in vitro antioxidant properties of the fractions: DPPH assay and lipid peroxidation (LOX) assay. Even though the results obtained by these two methods are frequently parallel, certain agents can exhibit substantial differences in these assays [31]. Generally, a compound effective in the DPPH assay can be considered as a free radical scavenger functioning in an organic solvent against a chemically pure molecule (i.e., the DPPH radical). LOX assay, on the other hand, is performed in a more complex ex vivo biological system containing lipids with unsaturated fatty acids; a substance active in this assay may protect these lipids from the spontaneous oxidation in aqueous conditions.

$\mathrm{DPPH}$ assay was performed with the concentration range of $0.001-0.15 \mathrm{mg} / \mathrm{mL}$ to characterize the free radical scavenging capacity of the prepared fractions. Fractions FR1 and FR2 exhibited no substantial activities in the utilized concentrations. Fractions FR3 and FR4 were moderately active, while FR5 and FR-W showed the highest potencies. FR6, containing significant amounts of phenolic compounds (compounds 1-3), was equipotent with the reference agent trolox. In agreement with these, lipid peroxidation assay showed that the antioxidant capacities of fractions FR3 and FR6 were close to that of trolox, while FR5 and FR-W were slightly less active. Fractions FR2 and FR4 exhibited moderate activities, and, similarly to the case of the DPPH assay, FR1 was inactive. Results of both assays are summarized in Table 1.

3.4. Effect on the In Vitro Glucose Consumption of Adipocytes. Although some minor changes could be observed in this bioassay, no statistically significant activities were found. This was somewhat surprising, since a lipophilic fraction, obtained by a simple solvent-solvent distribution from the hot water extract of the same plant collection, was previously 

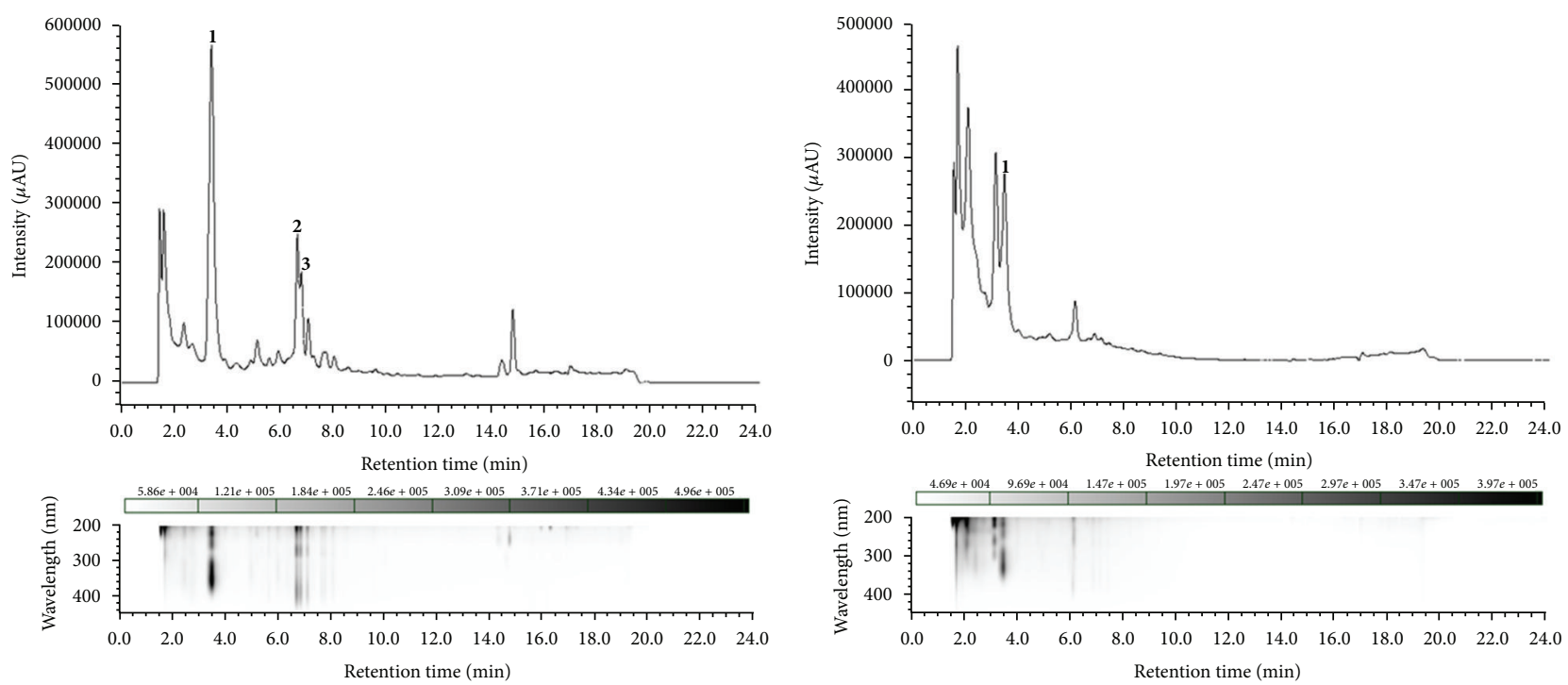

(a)
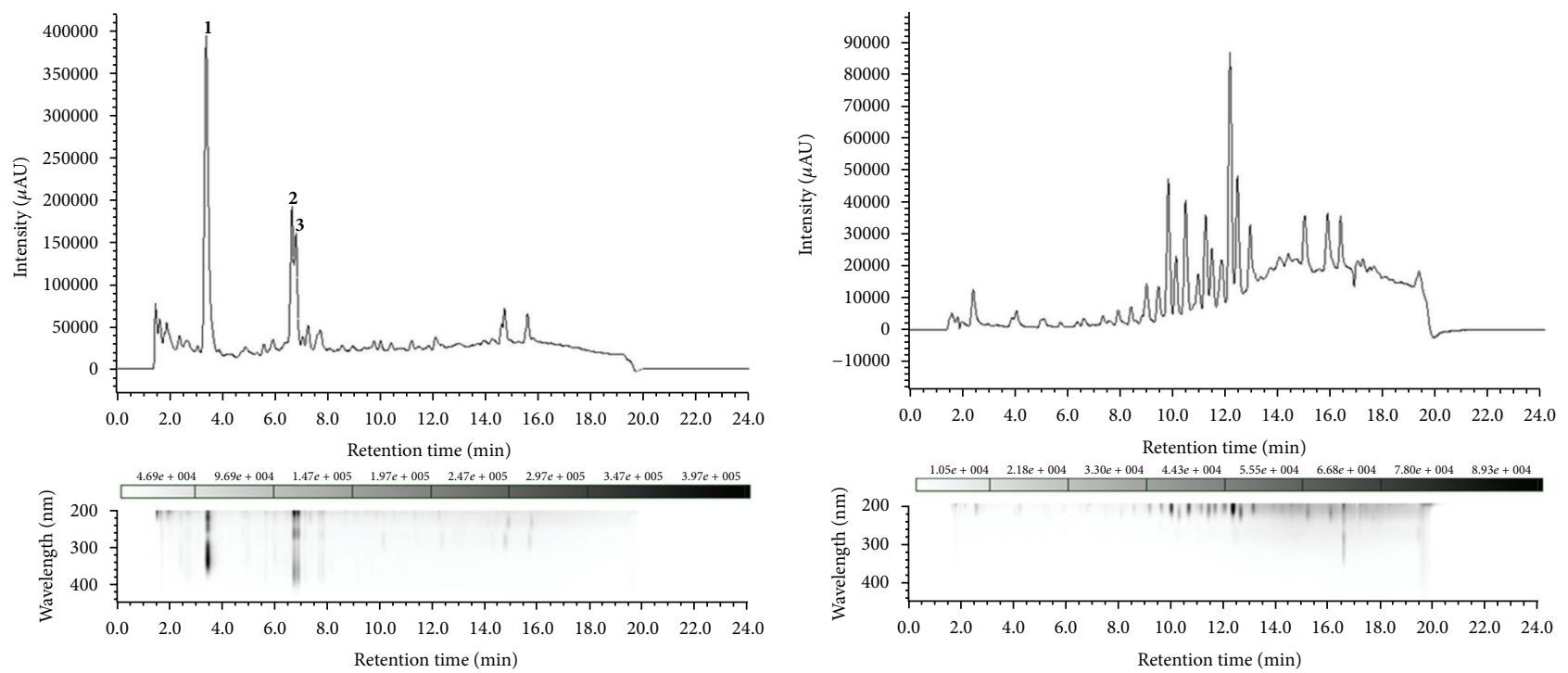

(c)
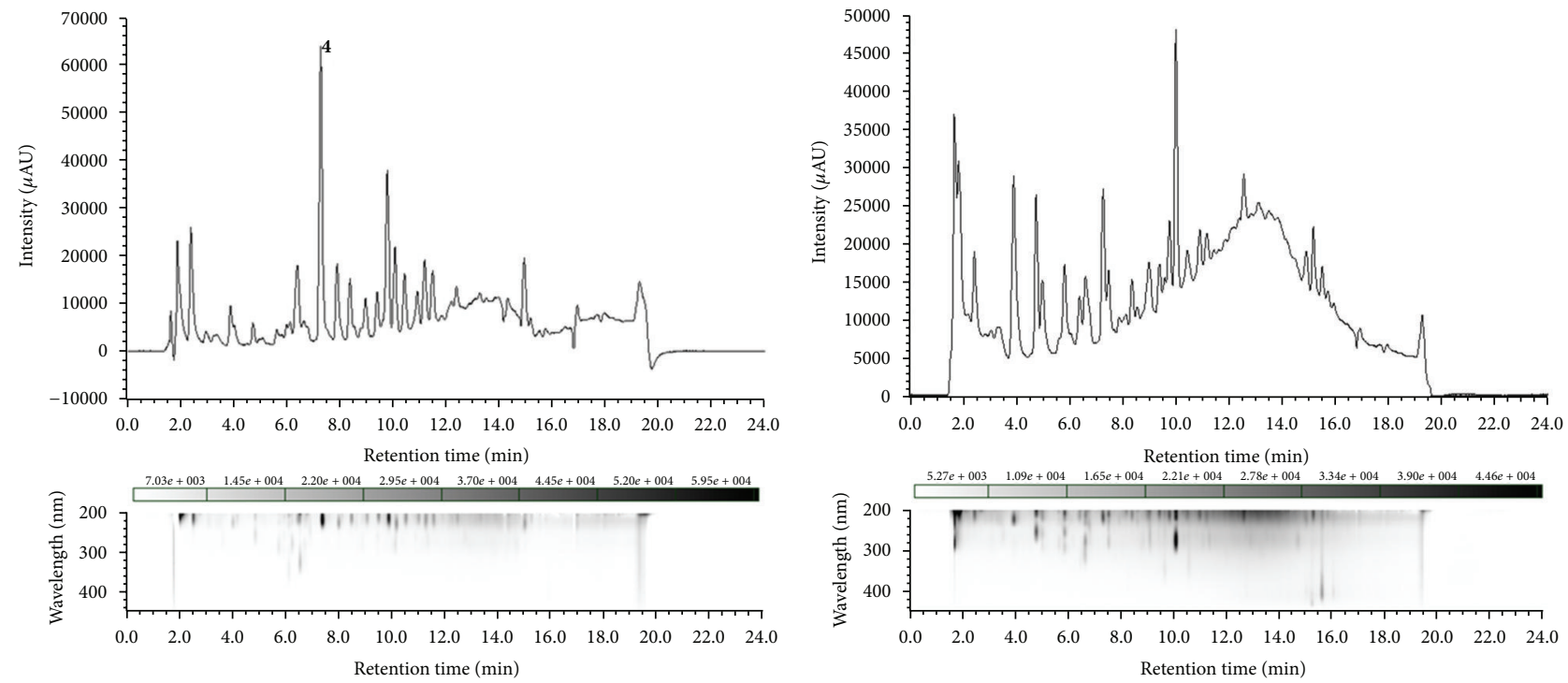

(e)

FIgURe 1: Continued. 


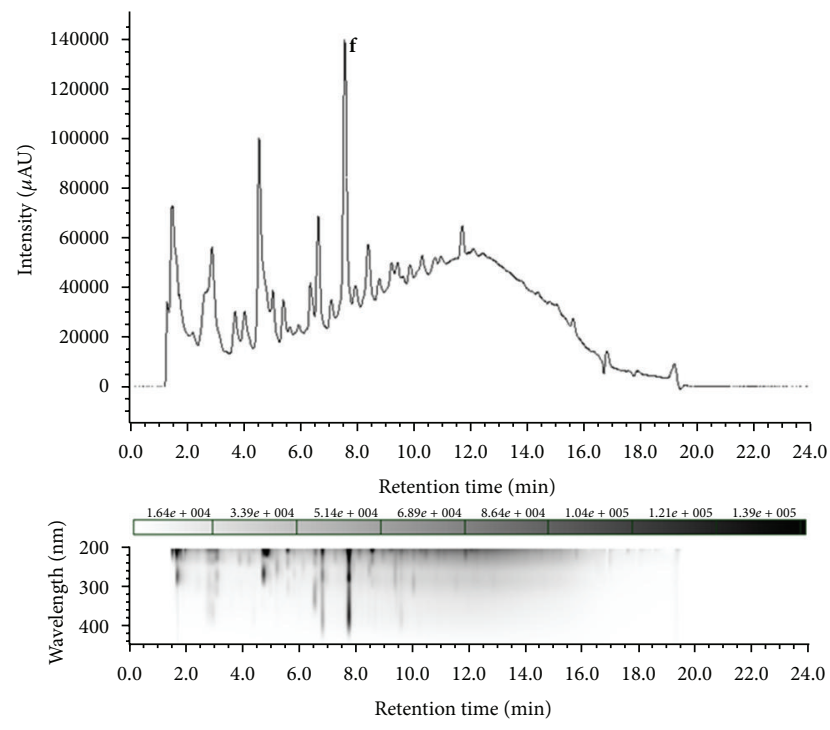

(g)
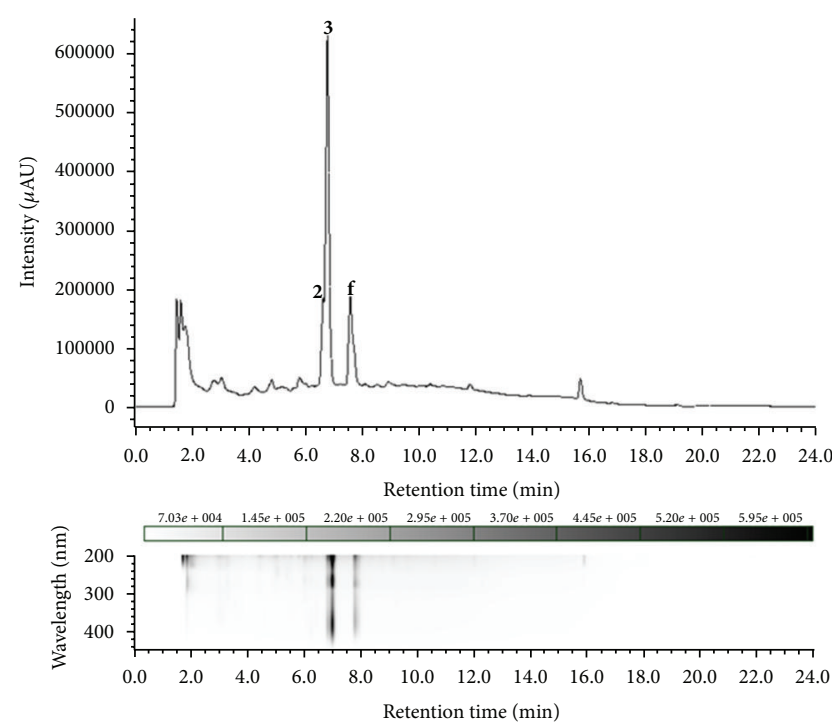

(h)

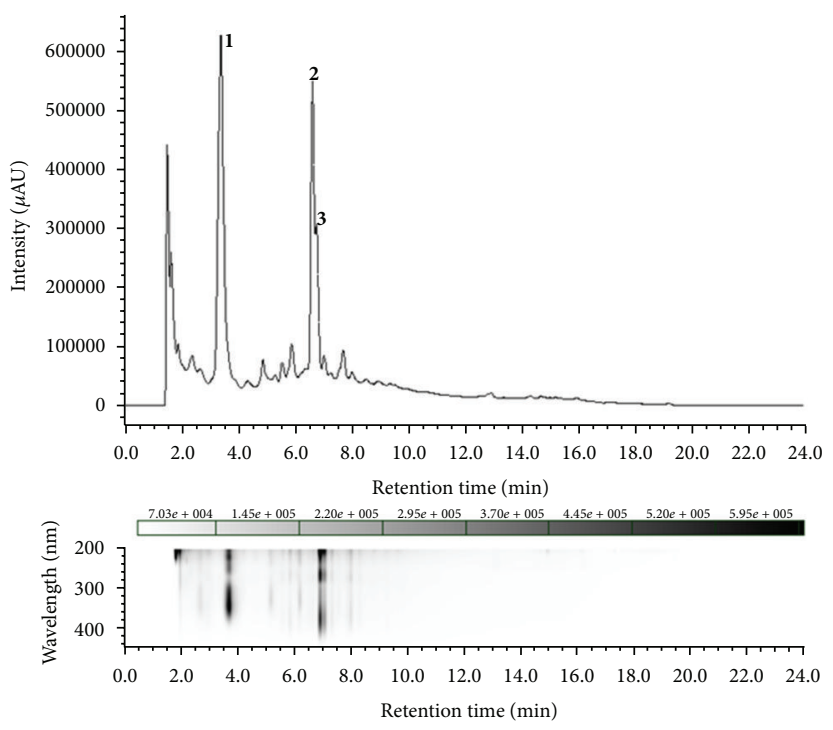

(i)

FIGURE 1: HPLC-DAD fingerprints of the samples and the corresponding maximum absorbance chromatograms from $\lambda=200$ to $450 \mathrm{~nm}$. (a) Crude extract (EX), (b) FR-W, (c) FR-B, and (d)-(i) FR1-FR6, respectively. Marked peaks represent chlorogenic acid (1), rutin (2), isoquercitrin (3), loliolide (4), and an unidentified flavone derivative (f).

found to exert strong effect in this test [19]. The most likely explanation is the low relative amount of the constituents responsible for this effect, based on which we can also conclude that increasing the glucose consumption of adipose tissue has little importance in the complex anti-diabetic activity of less processed phytotherapeutics originated from mulberry leaves.

3.5. Determination of the Antihyperuricemic Effects of the Fractions In Vivo. The serum uric acid concentration in rats is considerably low because it is metabolized into allantoin by the enzyme uricase. Therefore, uric acid accumulation was induced by a single administration of K-oxonate for the in vivo investigation of the antihyperuricemic properties of the fractions. Results are shown in Figure 3. Allopurinol (50 mg/kg intraperitoneally), used as positive control, substantially and significantly decreased the accumulation of uric acid. The lowest dose $(30 \mathrm{mg} / \mathrm{kg})$ of FR1, the highest dose $(120 \mathrm{mg} / \mathrm{kg})$ of FR2, and $60 \mathrm{mg} / \mathrm{kg}$ of FR5 exerted antihyperuricemic actions comparable to that of allopurinol. Unexpectedly, treatment with FR-W (60 and $120 \mathrm{mg} / \mathrm{kg}$ ) resulted in an elevation of serum uric acid levels. No clear dose-response relationships were detected for some of the fractions.

The renal excretion of uric acid is a complex and speciesdependent procedure involving its glomerular filtration, tubular secretion, and tubular reabsorption. Since these processes can independently be modulated with exogenous 
<smiles>O=C(/C=C/c1ccc(O)c(O)c1)O[C@@H]1C[C@@](O)(C(=O)O)C[C@H](O)[C@@H]1O</smiles><smiles>[R][CH]Oc1c(-c2ccc(O)c(O)c2)oc2cc(O)cc(O)c2c1=O</smiles>

2: $\mathrm{R}=\alpha$-L-rhamnopyranosyloxy 3: $\mathrm{R}=\mathrm{H}$<smiles>CC1(C)C[C@@H](O)C[C@@]2(C)OC(=O)C=C12</smiles>

4<smiles>OC[C@H]1NC[C@@H](O)[C@H](O)[C@@H]1O</smiles>

$1-\mathrm{DN}$

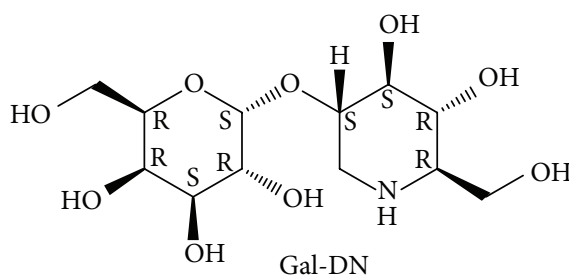

Gal-DN<smiles>OC[C@H]1NCC[C@H](O)[C@@H]1O</smiles>

Fagomine

FIGURE 2: Chemical structures of the compounds identified in the fractions: chlorogenic acid (1), rutin (2), isoquercitrin (3), loliolide (4), 1-deoxynojirimycin (1-DN), 2-O-alpha-D-galactopyranosyl-1-deoxynojirimycin (Gal-DN), and fagomine. Glu: $\beta$-D-glucopyranosyloxy.

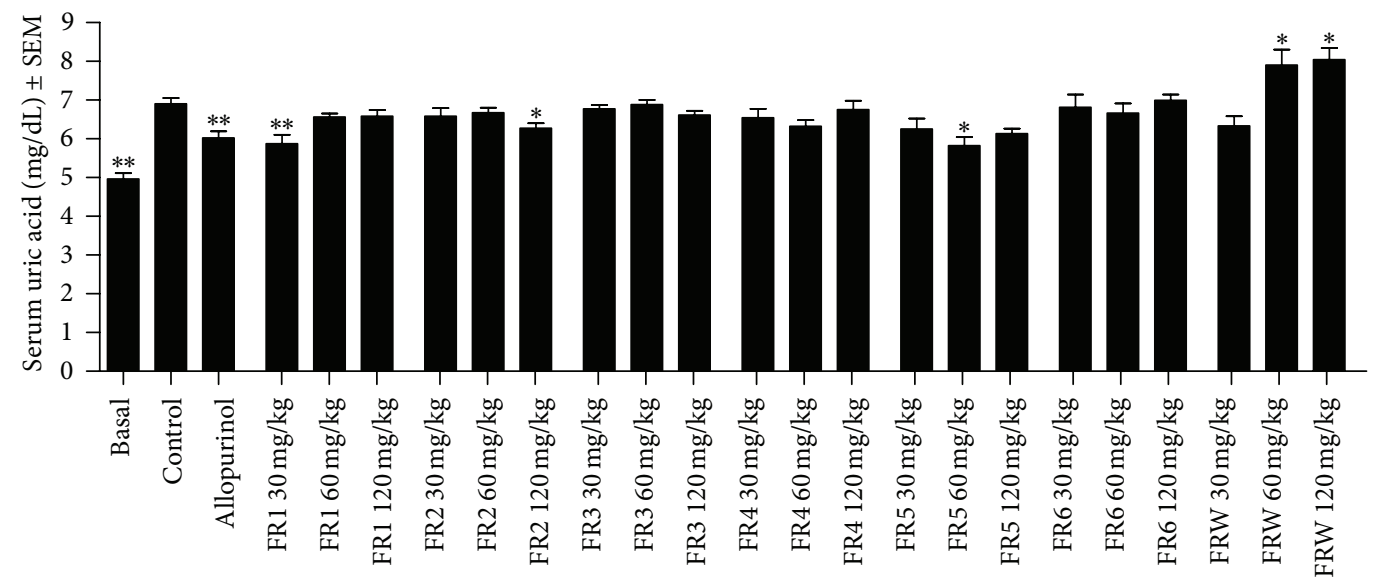

FIGURE 3: In vivo antihyperuricemic activity of the fractions obtained. Hyperuricemia was induced by a single administration of K-oxonate, $50 \mathrm{mg} / \mathrm{kg}$ of allopurinol was used as positive control, and samples were tested at 30,60 , and $120 \mathrm{mg} / \mathrm{kg}$. $*$ and $* *: P<0.05$ and 0.01 , respectively, as compared to the negative control by means of one-way ANOVA followed by Dunnett's multiple comparison test; $n=8$.

substances, the overall action of a drug is frequently biphasic. Aspirin at dosages of $>3 \mathrm{~g}$ /day promotes uricosuria by inhibition of the reabsorption while lower dosages (1-2 g/day) may cause uric acid retention, presumably by interfering with the tubular secretion [32]. This, together with the chemical complexity of the fractions, could provide a simple explanation for the unclear dose-response relationships observed in certain cases; several interactions between various constituents of the fractions might take place, in which the active components would influence these renal functions differently.

3.6. Determination of the Serum Antioxidant Capacity. The antioxidant capacities of the serum samples of the treated animals were determined by means of a photometric assay in which 2,2' -azino-bis(3-ethylbenzthiazoline-6-sulfonic acid) (ABTS) is converted into a chromogen radical cation $\left(\mathrm{ABTS}^{\bullet+}\right)$. The generation of radical cation is suppressed by antioxidants and can be detected as a decrease of color intensity; results of this assay are shown in Figure 4. Treatment with trolox $(10 \mathrm{mg} / \mathrm{kg})$ resulted in a substantial increase in the antioxidant capacity (expressed as trolox equivalents) but most of the tested fractions failed to induce significant change in this serum parameter. The higher doses of FR6 (60 and $120 \mathrm{mg} / \mathrm{kg}$ ) exhibited similar antioxidant effects to that of trolox, which effect can most likely be attributed to the high chlorogenic acid (1), rutin (2), and isoquercitrin (3) content of this fraction. On the other hand, $30 \mathrm{mg} / \mathrm{kg}$ of FR3 decreased the oxidative status of the serum, indicating a prooxidant potential for certain constituents. 


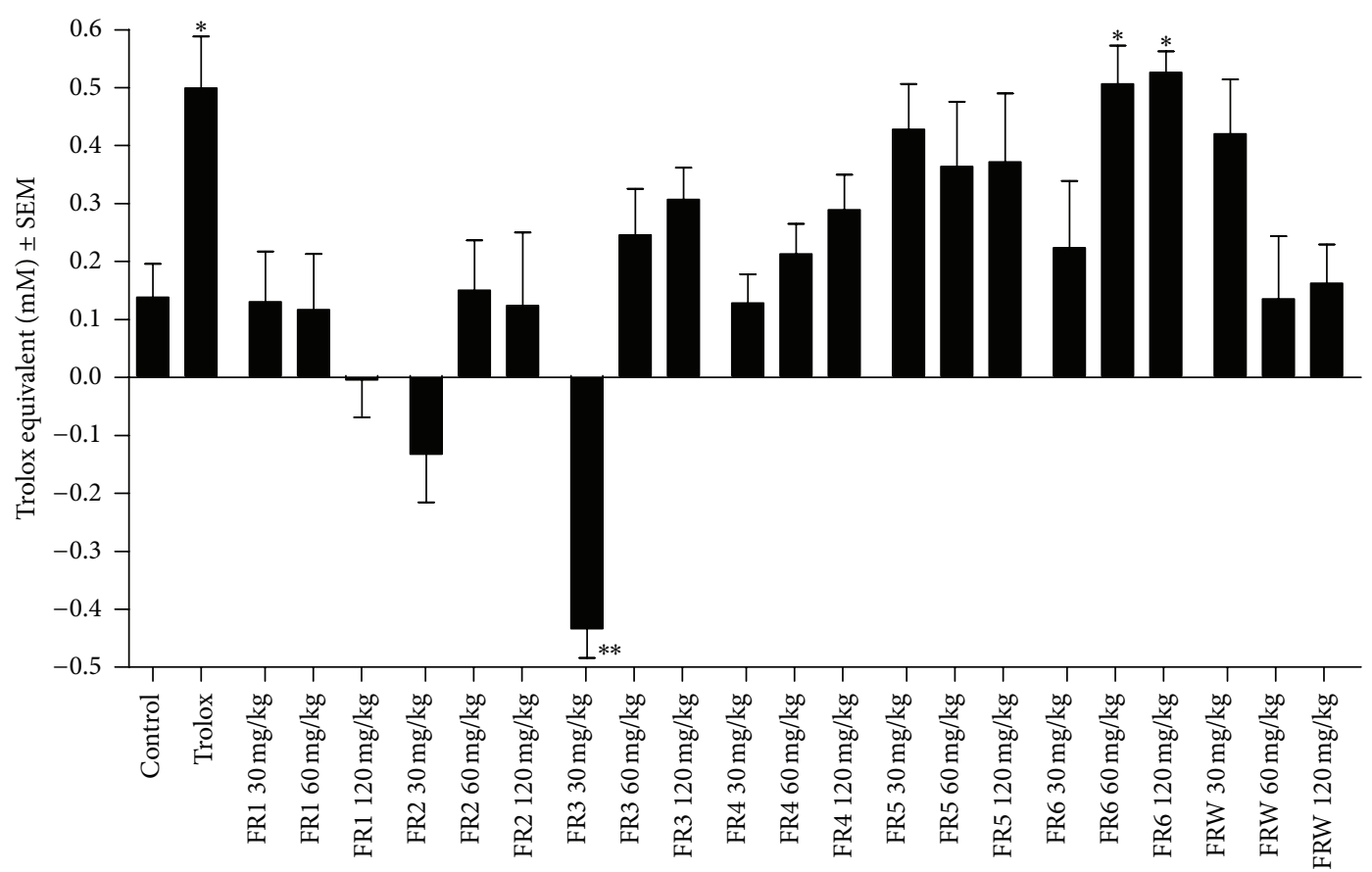

FIGURE 4: Effects on the serum antioxidant capacity in vivo. ${ }^{*} P<0.05$ as compared to the negative control by one-way ANOVA followed by Dunnett's multiple comparison test; $n=8$.

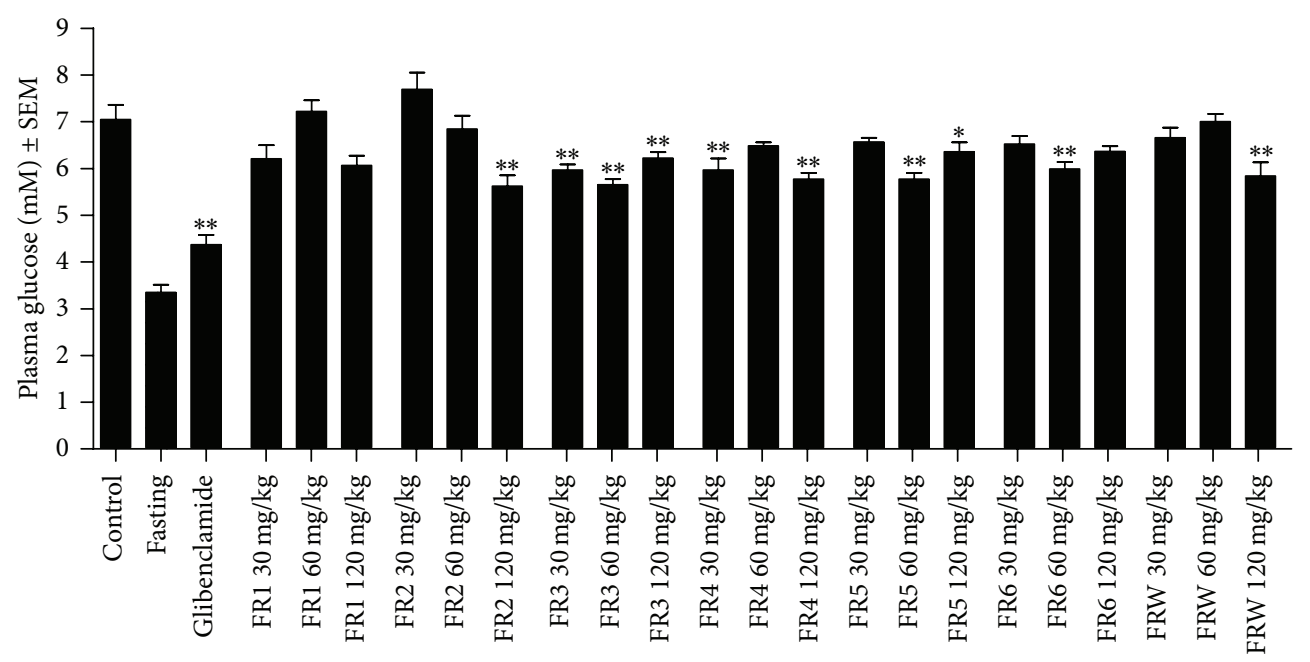

FIGURE 5: Effects on the postprandial hyperglycemia of normal rats after starch loading. $*$ and $* *: P<0.05$ and 0.01 , respectively, as compared to the negative control by one-way ANOVA followed by Dunnett's multiple comparison test; $n=8$. The fasting blood glucose level was determined in preliminary experiments, and its dataset was not included in the statistical evaluation.

3.7. Determination of the Postprandial Plasma Glucose Levels. Treatment with the positive control glibenclamide $(10 \mathrm{mg} / \mathrm{kg})$ resulted in a substantial and significant decrease of the postprandial plasma glucose levels obtained in the starch load model. FR1 was inactive up to $120 \mathrm{mg} / \mathrm{kg}$, while FR3 exhibited antihyperglycemic action at all applied doses. Fractions FR2, FR-W, and FR5 were effective at 120, 60, and $120 \mathrm{mg} / \mathrm{kg}$, respectively. Fractions FR4 and FR6 exhibited some antihyperglycemic properties but no clear dose-response relationships were observed; results are shown in Figure 5. It is worthy to note, however, that the present in vivo model investigated the effect of a single-dose administration on the postprandial hyperglycemia of normal rats after starch loading; therefore, these results can hardly be compared with those we obtained previously for a longer treatment in type 2 diabetic rats with ad libitum access to standard food [16].

\section{Conclusions}

The investigated extract of $M$. alba showed multiple beneficial bioactivities in view of both targeted chronic metabolic diseases. It can also be concluded, based on the different 
TABLE 1: In vitro antioxidant activities as calculated from the DPPH assay and from the inhibition of the spontaneous lipid peroxidation.

\begin{tabular}{lcc}
\hline Sample & $\begin{array}{c}\mathrm{DPPH} \\
\mathrm{EC}_{50}(\mu \mathrm{g} / \mathrm{mL})\end{array}$ & $\begin{array}{c}\text { Lipid peroxidation } \\
\mathrm{IC}_{50}(\mu \mathrm{g} / \mathrm{mL})\end{array}$ \\
\hline FR-W & 72.2 & 71.0 \\
FR1 & $-{ }^{\mathrm{a}}$ & $-{ }^{\mathrm{a}}$ \\
FR2 & $-{ }^{\mathrm{a}}$ & 138.0 \\
FR3 & 186.0 & 47.3 \\
FR4 & 245.0 & 114.0 \\
FR5 & 55.0 & 77.7 \\
FR6 & 21.7 & 55.8 \\
Trolox & 21.8 & 42.5 \\
\hline
\end{tabular}

Trolox: positive control in both cases.

${ }^{a}$ Exhibited no substantial activity in the applied concentration range.

effects exerted by the fractions, that separate compound groups are responsible for the individual actions, which have a significant potential for a positive combined effect.

FR1, FR2, and FR5 are of interest in view of the antihyperuricemic activity as potential uricosuric agents. FR2-6 were all found valuable for their antihyperglycemic activities, but FR3 was the strongest exerting significant effects at all administered doses. Somewhat unsurprisingly, FR6, containing most of the phenolic constituents, was found to be the strongest antioxidant both in vitro and in vivo, which makes this fraction particularly useful against the high oxidative stress present in both diabetes and chronic hyperuricemia.

Furthermore, considering our original objectives, fractions of relatively low value could also be revealed. Although the water phase of the first solvent-solvent extraction (FR$\mathrm{W}$ ) could effectively scavenge DPPH radicals in vitro and showed at least a weak antihyperglycemic activity in vivo (possibly due to the low iminosugar content of our sample), this fraction was also found to significantly increase the plasma uric acid levels; hence, it is potentially unwanted in a well-designed mulberry preparation. FR1, the less polar fraction that was eluted with dichloromethane from the silica column, was found inactive in most bioactivity tests except for its non-dose-dependent antihyperuricemic activity at 30 $\mathrm{mg} / \mathrm{kg}$ in vivo. This might be of interest for further research, but, due to the nearly $20 \%$ amount of this fraction by weight in the dry butanolic phase, removing this polarity range of constituents could as well be considered for increasing the overall therapeutic benefits of a phytotherapeutic product.

\section{Acknowledgments}

This work was supported by the Hungarian National Research Fund (OTKA PD75383), and it was performed within the framework of a bilateral mobility Grant from the National Science Council, Taiwan, and the Hungarian Academy of Sciences (102-2911-I-037-501 and SNK-79/2013). The authors acknowledge financial support from the Pick Szeged Zrt., Szeged, Hungary, Grants from the European Union cofunded by the European Social Fund (TAMOP-4.2.2/B-10/1-20100012, and TAMOP-4.2.2A-11/1/KONV-2012-0035), the Grant from the National Science Council of Taiwan (NSC 101-2314B-037-033), and support of the Fundação para a Ciência e a Tecnologia, Portugal (PEsT-OE/SAU/UI0074/2011). A. Martins acknowledges the Grant SFRH/BPD/81118/2011, FCT, Portugal and Professor Leonard Amaral for scientific discussion. The authors wish to express their special thanks to Ibolya Hevérné Herke for her contribution to the lab work.

\section{References}

[1] E. W. Campion, R. J. Glynn, and L. O. DeLabry, "Asymptomatic hyperuricemia: risks and consequences in the normative aging study," The American Journal of Medicine, vol. 82, no. 3, pp. 421426, 1987.

[2] E. Krishnan, B. J. Pandya, L. Chung, and O. Dabbous, "Hyperuricemia and the risk for subclinical coronary atherosclerosis: data from a prospective observational cohort study," Arthritis Research \& Therapy, vol. 13, p. R66, 2011.

[3] P. Higgins, J. Dawson, and M. Walters, "The potential for xanthine oxidase inhibition in the prevention and treatment of cardiovascular and cerebrovascular disease," Cardiovascular Psychiatry and Neurology, vol. 2009, Article ID 282059, 9 pages, 2009.

[4] P. Pacher, A. Nivorozhkin, and C. Szabó, “Therapeutic effects of xanthine oxidase inhibitors: renaissance half a century after the discovery of allopurinol," Pharmacological Reviews, vol. 58, no. 1, pp. 87-114, 2006.

[5] L. Changgui, H. Ming-Chia, and C. Shun-Jen, "Metabolic syndrome, diabetes, and hyperuricemia," Current Opinion in Rheumatology, vol. 25, no. 2, pp. 210-216, 2013.

[6] M. A. Suriyajothi, R. Sangeetha, and R. Venkateswari, "Activity of Xanthine oxidase in diabetics: its correlation with aging," Pharmacologyonline, vol. 2, pp. 128-133, 2011.

[7] S. Ryu, J. Song, B.-Y. Choi et al., "Incidence and risk factors for metabolic syndrome in Korean male workers, ages 30 to 39," Annals of Epidemiology, vol. 17, no. 4, pp. 245-252, 2007.

[8] X. Sui, T. S. Church, R. A. Meriwether, F. Lobelo, and S. N. Blair, "Uric acid and the development of metabolic syndrome in women and men," Metabolism, vol. 57, no. 6, pp. 845-852, 2008.

[9] H. Ito, M. Abe, M. Mifune et al., "Hyperuricemia is independently associated with coronary heart disease and renal dysfunction in patients with type 2 diabetes mellitus," PloS ONE, vol. 6, no. 11, Article ID e27817, 2011.

[10] C. L. T. Chang, Y. Lin, A. P. Bartolome, Y. C. Chen, S. C. Chiu, and W. C. Yang, "Herbal therapies for type 2 diabetes mellitus: chemistry, biology, and potential application of selected plants and compounds," Evidence-Based Complementary and Alternative Medicine, vol. 2013, Article ID 378657, 33 pages, 2013.

[11] Z. Wang, J. Wang, and P. Chan, "Treating type 2 diabetes mellitus with traditional Chinese and Indian medicinal herbs," Evidence-Based Complementary and Alternative Medicine, vol. 2013, Article ID 343594, 17 pages, 2013.

[12] D. Bensky and A. Gamble, Chinese Herbal Medicine, Materia Medica, Eastland Press, Seattle, Wash, USA, 1986.

[13] J. Anjaria, M. Parabia, G. Bhatt, and R. Khamar, Nature Heals, A Glossary of Selected Indigenous Medicinal Plants of India, Sristi Innovations, Ahmedabad, India, 2002.

[14] A. N. B. Singab, H. A. El-Beshbishy, M. Yonekawa, T. Nomura, and T. Fukai, "Hypoglycemic effect of Egyptian Morus alba root bark extract: effect on diabetes and lipid peroxidation of 
streptozotocin-induced diabetic rats," Journal of Ethnopharmacology, vol. 100, no. 3, pp. 333-338, 2005.

[15] I. Lemus, R. García, E. Delvillar, and G. Knop, "Hypoglycaemic activity of four plants used in Chilean popular medicine," Phytotherapy Research, vol. 13, no. 2, pp. 91-94, 1999.

[16] A. Hunyadi, A. Martins, T. J. Hsieh, A. Seres, and I. Zupkó, "Chlorogenic acid and rutin play a major role in the in vivo antidiabetic Activity of Morus alba leaf extract on type II diabetic rats," PloS ONE, vol. 7, no. 11, Article ID e50619, 2012.

[17] M. Mudra, N. Ercan-Fang, L. Zhong, J. Furne, and M. Levitt, "Influence of mulberry leaf extract on the blood glucose and breath hydrogen response to ingestion of $75 \mathrm{~g}$ sucrose by type 2 diabetic and control subjects," Diabetes Care, vol. 30, no. 5, pp. 1272-1274, 2007.

[18] T. Kimura, K. Nakagawa, H. Kubota et al., "Food-grade mulberry powder enriched with 1-deoxynojirimycin suppresses the elevation of postprandial blood glucose in humans," Journal of Agricultural and Food Chemistry, vol. 55, no. 14, pp. 5869-5874, 2007.

[19] A. Hunyadi, K. Veres, B. Danko et al., "In vitro anti-diabetic activity and chemical characterization of an apolar fraction of Morus alba leaf water extract," Phytotherapy Research, vol. 27, pp. 847-851, 2013.

[20] Y. W. Shia, C. P. Wang, X. Wang et al., "Uricosuric and nephroprotective properties of Ramulus Mori ethanol extract in hyperuricemic mice," Journal of Ethnopharmacology, vol. 143, no. 3, pp. 896-904, 2012.

[21] C.-P. Wang, Y. Wang, X. Wang et al., "Mulberroside A possesses potent uricosuric and nephroprotective effects in hyperuricemic mice," Planta Medica, vol. 77, no. 8, pp. 786-794, 2011.

[22] Z. Yu, P. F. Wing, and C. H. K. Cheng, "The dual actions of morin $\left(3,5,7,2^{\prime}, 4^{\prime}\right.$-pentahydroxyflavone) as a hypouricemic agent: uricosuric effect and xanthine oxidase inhibitory activity," Journal of Pharmacology and Experimental Therapeutics, vol. 316, no. 1, pp. 169-175, 2006.

[23] Z. Yu, P. F. Wing, and C. H. K. Cheng, "Morin $\left(3,5,7,2^{\prime}, 4^{\prime}-\right.$ pentahydroxyflavone) exhibits potent inhibitory actions on urate transport by the human urate anion transporter (hURAT1) expressed in human embryonic kidney cells," Drug Metabolism and Disposition, vol. 35, no. 6, pp. 981-986, 2007.

[24] K. Nakagawa, K. Ogawa, O. Higuchi, T. Kimura, T. Miyazawa, and M. Hori, "Determination of iminosugars in mulberry leaves and silkworms using hydrophilic interaction chromatographytandem mass spectrometry," Analytical Biochemistry, vol. 404, no. 2, pp. 217-222, 2010.

[25] H. G. Vogel, Ed., Drug Discovery and Evaluation: Pharmacological Assays, Springer, Berlin, Germany, 2002.

[26] Z. Hajdú, J. Hohmann, P. Forgo et al., "Diterpenoids and flavonoids from the fruits of Vitex agnus-castus and antioxidant activity of the fruit extracts and their constituents," Phytotherapy Research, vol. 21, no. 4, pp. 391-394, 2007.

[27] I. Zupkó, J. Hohmann, D. Rédei, G. Falkay, G. Janicsák, and I. Máthé, "Antioxidant activity of leaves of Salvia species in enzyme-dependent and enzyme-independent systems of lipid peroxidation and their phenolic constituents," Planta Medica, vol. 67 , no. 4 , pp. 366-368, 2001.

[28] I. Fridovich, "The competitive inhibition of uricase by oxonate and by related derivatives of s-triazines," The Journal of biological chemistry, vol. 240, pp. 2491-2494, 1965.

[29] P. Trinder, "Determination of glucose in blood using oxidase with an alternative oxygen acceptor," Annals of Clinical Biochemistry, vol. 6, pp. 24-27, 1969.
[30] C. J. Zuurbier, F. J. Hoek, J. Van Dijk et al., "Perioperative hyperinsulinaemic normoglycaemic clamp causes hypolipidaemia after coronary artery surgery," British Journal of Anaesthesia, vol. 100, no. 4, pp. 442-450, 2008.

[31] R. Minorics, T. Szekeres, G. Krupitza et al., "Antiproliferative effects of some novel synthetic solanidine analogs on HL-60 human leukemia cells in vitro," Steroids, vol. 76, no. 1-2, pp. 156$162,2011$.

[32] D. Caspi, E. Lubart, E. Graff, B. Habot, M. Yaron, and R. Segal, "The effect of mini-dose aspirin on renal function and uric acid handling in elderly patients," Arthritis and Rheumatism, vol. 43, pp. 103-108, 2000. 


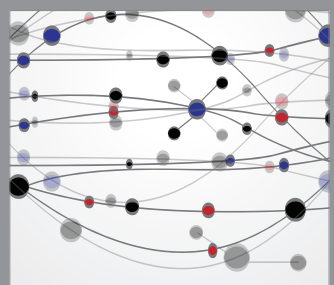

The Scientific World Journal
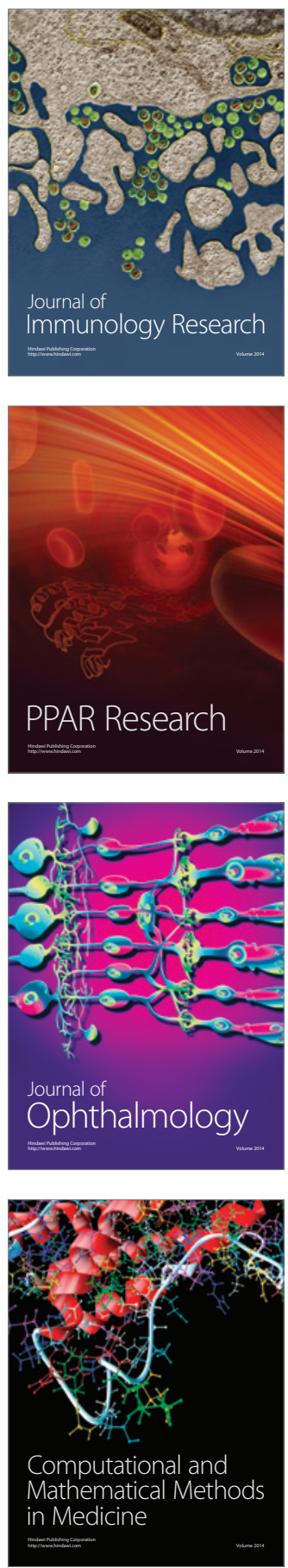

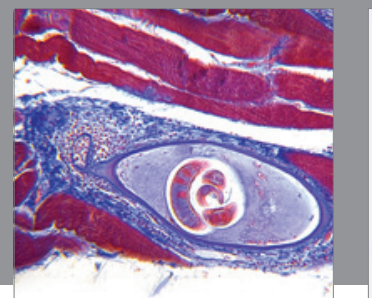

Gastroenterology

Research and Practice
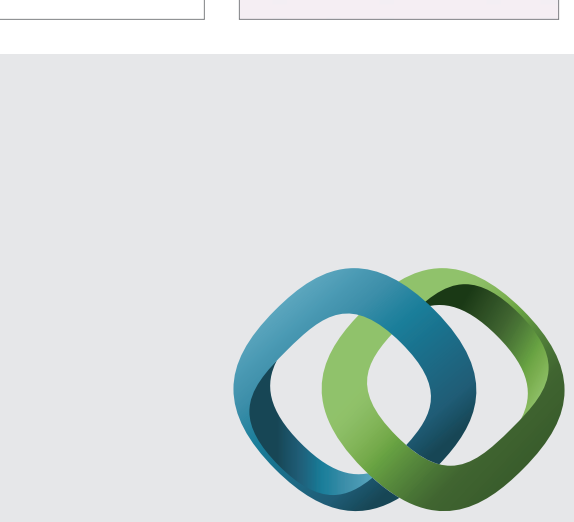

\section{Hindawi}

Submit your manuscripts at

http://www.hindawi.com
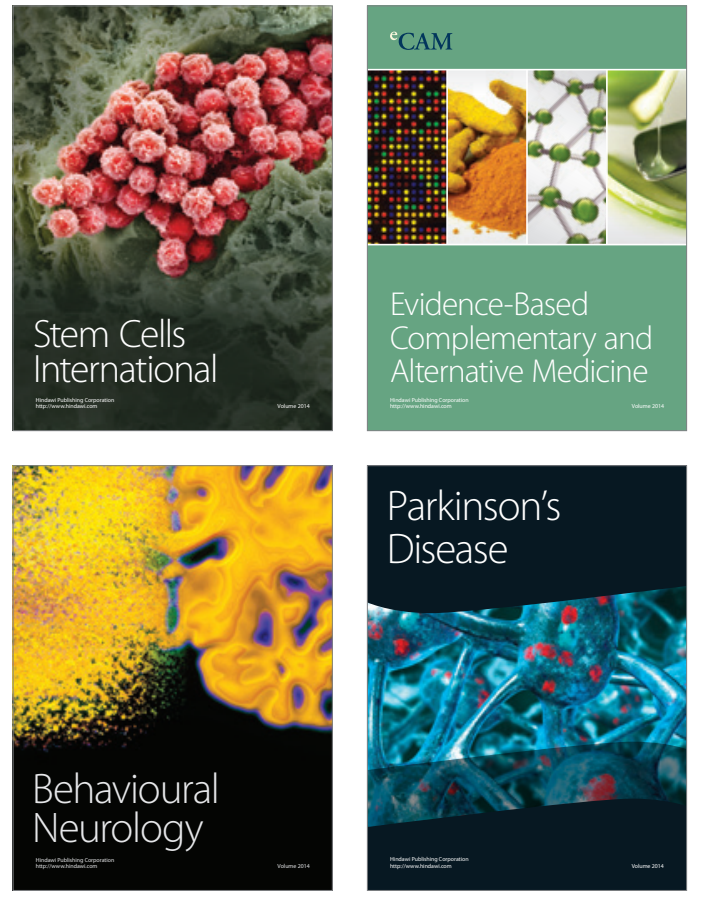
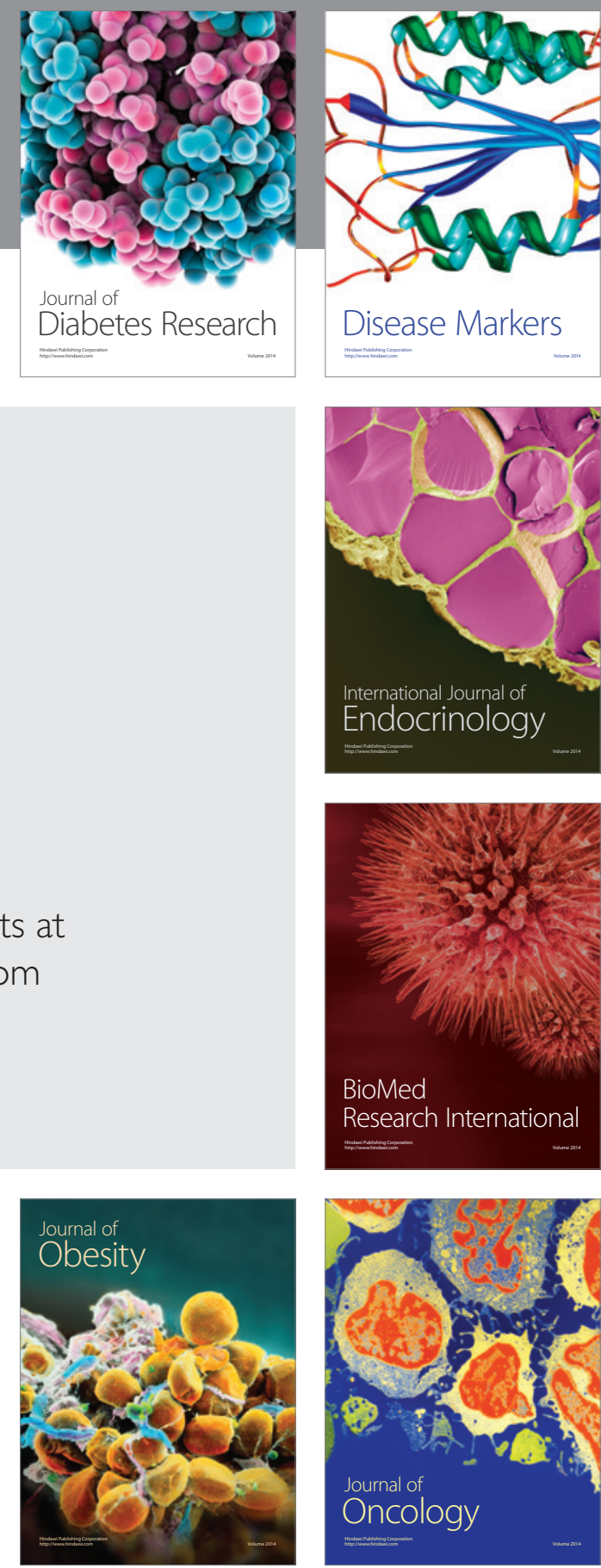

Disease Markers
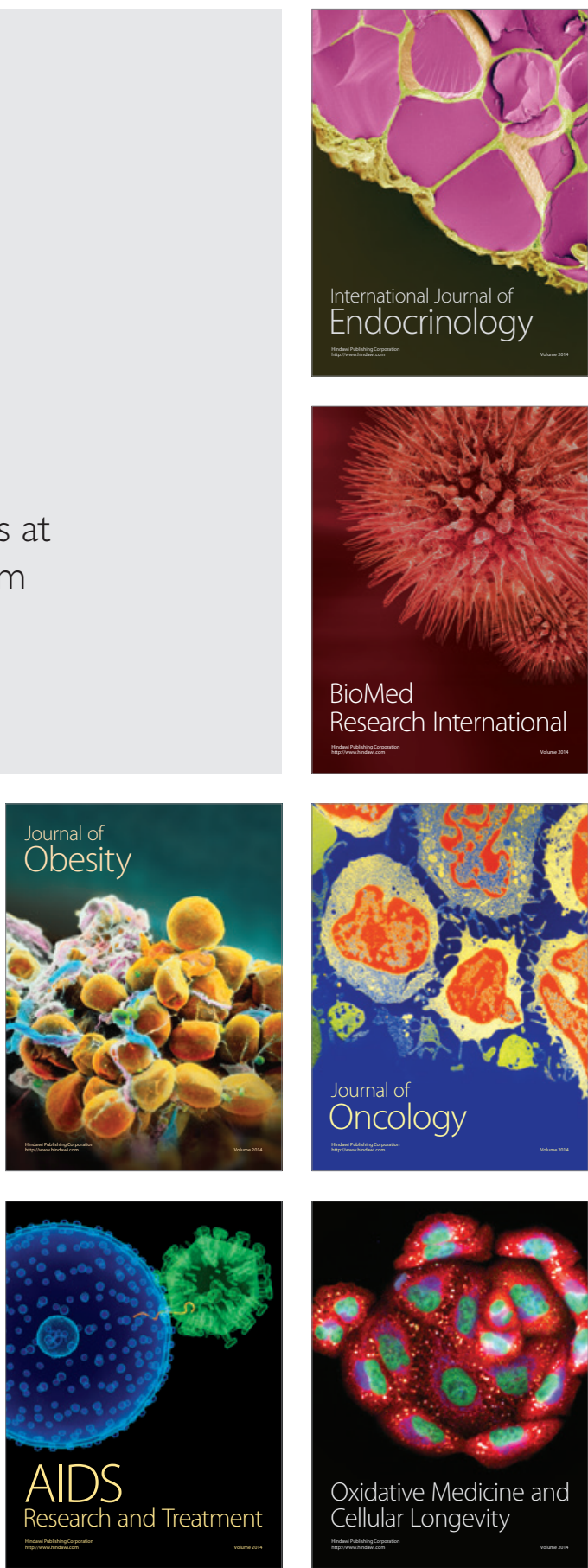